\title{
Analisis Pelatihan, Pengembangan, dan Teknologi Informasi Terhadap Kinerja Karyawan Pada KPN "JAYA" Guru SDN Raba Kota Bima
}

\author{
Aan Hidayat, Mulyadin* \\ Program Studi Manajemen, Sekolah Tinggi Ilmu Ekonomi (STIE) Bima, Kota Bima, Indonesia. \\ Email : ${ }^{1}$ aan319691@gmail.com, ${ }^{2, *}$ yadinmulyadin19@gmail.com \\ Email Penulis Korespondensi: yadinmulyadin19@gmail.com \\ Submitted: 12/06/2021; Accepted: 20/08/2021; Published: 30/08/2021
}

\begin{abstract}
Abstrak-Penelitian ini bertujuan untuk mengetahui pengaruh pelatihan, pengembangan, dan teknologi informasi terhadap kinerja karyawan pada KPN “Jaya" Guru SDN Raba. Populasi berjumlah 45 orang pegawai dan sample berjumlah 45 pegawai dan penelitian bersifat asosiatif. Tekhnik pengumpulan data yaitu observasi, dan pengisian kuesioner, dan studi pustaka. Variabel bebas dan terikat adalah variabel yang di gunakan pada penelitian ini. Variabel bebas adalah pelatihan (X1), pengembangan (X2), dan teknologi informasi (X3) dan variabel terikat adalah kinerja karyawan (Y). Teknik analisis menggunakan analisa kuantitatif yaitu analisis regresi berganda, koofisien korelasi, dan koofisien determinasi. uji hipotesis menggunakan uji t. hasil uji pengujian hipotesis dengan mengunakan uji t diperoleh thitung Variabel X1 $=(3,775)$ Variabel X2 $=(2,800)$ Variabel X3 $=(2,845)$ lebih besar dari tabel $(2,016)$ kemudian dapat disimpulkan bahwa terdapat pengaruh antara pelatihan, pengembangan, dan teknologi informasi terhadap kinerja karyawan pada KPN “Jaya” Guru SDN Raba.
\end{abstract}

Kata Kunci: Pelatihan; Pengembangan; Teknologi Informasi; Kinerja Karyawan

\begin{abstract}
This study aims to determine the effect of training, development, and information technology on employee performance at KPN "Jaya" Guru SDN Raba. The population is 45 employees and the sample is 45 employees and the research is associative. Data collection techniques are observation, and filling out questionnaires, and literature study. The independent and dependent variables are the variables used in this study. The independent variables are training (X1), development (X2), and information technology (X3) and the dependent variable is employee performance $(\mathrm{Y})$. The analysis technique uses quantitative analysis, namely multiple regression analysis, correlation coefficient, and determination coefficient. hypothesis testing using t test. the results of hypothesis testing using t test obtained tcount Variable $\mathrm{X} 1=(3.775)$ Variable $\mathrm{X} 2=(2.800)$ Variable $\mathrm{X} 3=(2.845)$ is greater than ttable $(2.016)$ then it can be concluded that there is an influence between training, development, and information technology on employee performance at KPN “Jaya” Guru SDN Raba.
\end{abstract}

Keywords: Training; Development; Information Technology; Employee Performance

\section{PENDAHULUAN}

Manusia merupakan faktor paling berpengaruh bagi berlangsungnya kehidupan sehari-hari. Melalui akal pikiran, manusia mampu menciptakan sesuatu yang menjadi penggerak sebuah organisasi dan mampu menciptakan kemudahan dalam berlangsungnya suatu kegiatan ekonomi. Di era sekarang ini, sudah banyak manfaat dan kemudahan dalam bidang ekonomi baik dalam bertransaksi pembelian maupun transaksi pinjaman yang dapat dirasakan oleh manusia. Setiap organisasi atau perusahaan dalam melakukan kegiatan bisnis mereka, terutama di era globalisasi sekarang ini membutuhkan faktor-faktor produksi (input) yang mampu diolah atau diproses secara optimal dengan harapan akan menghasilkan hasil (output) yang maksimal bagi perusahaan tersebut. Adapun faktor-faktor produksi tersebut antara lain adalah alat-alat atau mesin produksi, tempat, Sumber Daya Alam (SDA), modal, teknologi, informasi yang aktual, dan Sumber Daya Manusia (SDM). Sumber daya manusia atau tenaga kerja adalah salah satu faktor produksi yang diperlukan selain tanah, modal, teknologi dan kewirausahaan (entrepreneurship) untuk menghasilkan suatu output dalam perekonomian.

Salah satu kemudahan tersebut dapat dirasakan berkat adanya koperasi yang bertujuan untuk mengembangkan potensi dan kemempuan ekonomi anggota dan masyarakat, berupaya mempertinggi kualitas kehidupan manusia, memperkokoh perekonomian rakyat, dan mengembangkan perekonomian nasional. Keberhasilan suatu koperasi tentu tidak terlepas dari peran anggota organisasi yang baik. Organisasi yang baik adalah organisasi yang berusaha meningkatkan kesejahteraan dan kemampuan sumber daya manusianya, karena itu merupakan faktor kunci untuk meningkatkan kinerja para karyawan . Dalam menghadapi era globalisasi, koperasi dituntut untuk bekerja lebih efektif dan efisien lagi, dikarenakan persaingan yang semakin ketat dan banyaknya kompetitor dimana-mana. Memperhatikan kedisiplinan kepada karyawan bisa menjadi salah satu acuan untuk mengelola kinerja karyawan secara efektif dan efisien.

Karyawan-karyawan baru membutuhkan pelatihan-pelatihan sebelum mereka dapat menjalankan tugas-tugas yang menjadi kewajibannya. Sedangkan bagi karyawan lama, mereka membutuhkan pelatihan dan pengembangan karena adanya tuntutan dari tugas-tugasnya yang sekarang, atau untuk mempersiapkan dirinya bila ditransfer atau dipromosikan pada jabatan yang lain. Pelatihan dan pengembangan yang diberikan pada para karyawan juga sering mendorong para karyawan untuk bekerja lebih keras. Hal ini disebabkan karena karyawan- karyawan yang telah mengerti dengan baik tugas-tugas dan tanggung jawabnya akan berusaha untuk mencapai level kerja yang lebih tinggi. Pelatihan dimaksudkan untuk membantu meningkatkan kemampuan para karyawan melaksanakan tugasnya, sedangkan pengembangan lebih berorientasi pada peningkatan produktivitas kerja para karyawan di masa depan. Manfaat pelatihan yang ditempuh dapat berlanjut sepanjang karier karyawan tersebut. Ini berarti bahwa suatu pelatihan dapat bersifat 
pengembangan bagi karyawan bersangkutan karena pelatihan mempersiapkan karyawan untuk memikul tanggung jawab yang lebih besar di masa depan. Kesadaran para pengusaha akan arti pentingnya pelatihan dan pengembangan bagi karyawan untuk dapat mengikuti adanya perubahan-perubahan teknologi yang akan dipakai perusahaan, mendorong peranan pelatihan dan pengembangan semakin penting dalam kegiatan perusahaan.

Dalam hal ini karyawan pada KPN Jaya SDN Raba sangat membutuhkan pelatihan dan pengembangan untuk memaksimalkan tentang pengetahuan mengenai tekhnologi informasi untuk melatih dan memaksimalkan kinerja karyawan yang sangat minim terkait tekhnologi informasi. Perusahaan pun harus memberikan pelatihan dan pengembangan tekhnologi informasi, pelatihan juga dibutuhkan untuk melatih skil kerja karyawan dan pengembangan agar dapat mencapai tujuan pada perusahaan atau organisasi.

Dalam melakuan Pra Survey peneliti melakukan wawancara terhadap Ketua KPN Jaya pada tanggal 20 Desember 2020 dan di temukan hasil dimana kurangnya kemampuan Karyawan terkait Tekonologi yang digunakan pada Dunia Perkoperasian.

Berdasarkan uraian tentang program pelatihan dan pengembangan bagi peningkatan kinerja karyawan di atas, maka penulis bermaksud untuk meneliti apakah ada pengaruh positif pengaruh program pelatihan dan pengembangan terhadap produktivitas karyawan atau tidak.

\section{METODE PENELITIAN}

Populasi dalam penelitian ini adalah karyawan yang bertugas di KPN “Jaya” Guru SDN Raba yang berjumlah 45 orang. Sampel pada penelitian ini adalah seluruh kryawan KPN “Jaya” guru SDN Raba yang berjumlah 45 orang.

Metode penelitian yang digunakan adalah metode asosiatif untuk mengetahui pengaruh antara dua variabel atau lebih (Sugiyono, 2013:57). Data yang digunakan adalah data primer, kuesioner atau angket dengan skala likert. Teknik pengumpulan data menggunakan kuesioner dengan skala likert yang berisi sejumlah beberapa pernyataan untuk dijawab oleh responden.

Tabel 1. Skala Pengukuran

\begin{tabular}{clc}
\hline No & \multicolumn{1}{c}{ Jawaban } & Nilai Skor \\
\hline 1 & Sangat Setuju (SS) & 5 \\
2 & Setuju (S) & 4 \\
3 & Cukup Setuju (CS) & 3 \\
4 & Tidak Setuju (TS) & 2 \\
5 & Sangat Tidak Setuju (STS) & 1 \\
\hline
\end{tabular}

Teknik pengumpulan data yang digunakan yaitu, wawancara, observasi, angket/kuesioner, dan studi pustaka. Lokasi Penelitian dilakukan di KPN “Jaya' Guru SDN Raba bertempat Jl. Soekarno Hatta No.1 Kota Bima dengan waktu penelitian 3 bulan yaitu pada bulan April sampai dengan bulan Juni tahun 2021.

Teknik analisis data yang digunakan antara lain: uji validitas, uji reliabilitas, regresi linier berganda, koofisien korelasi, koefisien determinasi, uji t, dan uji f yang semunya menggunakan bantuan SPSS 23 for Windows demi ketelitian hasil penelitian.

Hipotesis merupakan dugaan atau jawaban sementara dari sebuah penelitian sebelum dilakukan penelitian lanjutan untuk membuktikannya. Berdasarkan teori dan permasalahan diatas, dapat diajukan hipotesis sebagai berikut:"Terdapat pengaruh Analisis Pelatihan Pengembangan Teknologi Terhadap Kinerja Karyawan Kpn Jaya Sdn Raba"

\section{Hipotesis statistik}

H1 = Di duga terdapat pengaruh Pelatihan Terhadap Kinerja Karyawan KPN "Jaya” SDN Raba.

H2 = Di duga terdapat pengaruh Pengembangan Terhadap Kinerja Karyawan KPN "Jaya” SDN Raba

H3 = Di duga terdapat pengaruh teknologi informasi Terhadap Kinerja Karyawan KPN "Jaya” SDN Raba

\section{HASIL DAN PEMBAHASAN}

\section{a. Uji Validitas}

Tabel 2. Hasil Perhitungan Uji Validitas

\begin{tabular}{ccccc}
\hline Variabel & Pernyataan & Rhitung & Rtabel & Kriteria \\
\hline & 1 & 0,511 & 0,300 & Valid \\
Pelatih & 2 & 0,665 & 0,300 & Valid \\
an (X1) & 3 & 0,630 & 0,300 & Valid \\
& 4 & 0,357 & 0,300 & Valid \\
Pengembangan & 5 & 0,403 & 0,300 & Valid \\
& 6 & 0,393 & 0,300 & Valid \\
\hline
\end{tabular}


Ekonomi, Keuangan, Investasi dan Syariah (EKUITAS)

Vol 3, No 1, Agustus 2021, Hal 1-6

ISSN 2685-869X (media online)

DOI 10.47065/ekuitas.v3i1.770

\begin{tabular}{ccccc}
\hline Variabel & Pernyataan & Rhitung & Rtabel & Kriteria \\
\hline (X2) & 2 & 0,653 & 0,300 & Valid \\
& 3 & 0,599 & 0,300 & Valid \\
& 4 & 0,527 & 0,300 & Valid \\
& 1 & 0,571 & 0,300 & Valid \\
Teknologi & 2 & 0,629 & 0,300 & Valid \\
Informasi (X3) & 3 & 0,595 & 0,300 & Valid \\
& 4 & 0,499 & 0,300 & Valid \\
& 5 & 0,383 & 0,300 & Valid \\
& 6 & 0,555 & 0,300 & Valid \\
& 1 & 0,568 & 0,300 & Valid \\
& 2 & 0,562 & 0,300 & Valid \\
Kinerja & 3 & 0,475 & 0,300 & Valid \\
Karyawan (Y) & 4 & 0,578 & 0,300 & Valid \\
& 5 & 0,711 & 0,300 & Valid \\
& 6 & 0,497 & 0,300 & Valid \\
& 8 & 0,743 & 0,300 & Valid \\
& 9 & 0,585 & 0,300 & Valid \\
& 10 & 0,502 & 0,300 & Valid \\
& 11 & 0,752 & 0,300 & Valid \\
& 12 & 0,477 & 0,300 & Valid \\
& 9 & 0,300 & Valid \\
\hline
\end{tabular}

Sumber: data Primer Diolah, 2021

Berdasarkan table 1. diatas dapat dilihat bahwa hasil dari Uji Validitas seluruh item pertanyaan bernilai valid. Hal ini ditunjukan dari nilai Rhitung > nilai Rtabel.

\section{b. Uji Reliabilitas}

Tabel 2. Hasil Uji Reliabilitas

\begin{tabular}{lccc}
\hline Variabel penelitian & Cronbach's alpha & Batas normal & Keterangan Reliabel \\
\hline Pelatihan & 0,655 & 0,6 & Reliabel \\
Pengembangan & 0,602 & 0,6 & Reliabel \\
Teknologi Informasi & 0,671 & 0,6 & Reliabel \\
Disiplin Pegawai & 0,825 & 0,6 & Reliabel \\
\hline
\end{tabular}

Sumber: data Primer Diolah, 2020

Dari perhitungan dengan menggunakan teknik Alpha Croncbach yang terdapat pada tabel 2 diatas, dapat disimpulkan bahwa kuisioner dalam penelitian ini ditanyatakan reliebel atau konsisten, karena nilai Cronbach Alpha lebih dari 0,600. Sesuai dengan dasar pengambilan keputusan uji reliabilitias, jika nilai Cronbach Alpha >0,600 maka kuisioner atau angket dinyatakan reliebel atau konsisten.

\section{c. Analisis Regresi Berganda}

Tabel 3. Hasil analisis regresi berganda

\begin{tabular}{|c|c|c|c|c|c|c|c|c|}
\hline \multicolumn{9}{|c|}{ Coefficients $^{\mathrm{a}}$} \\
\hline \multirow{2}{*}{\multicolumn{2}{|c|}{ Model }} & \multicolumn{2}{|c|}{$\begin{array}{l}\text { Unstandardized } \\
\text { Coefficients }\end{array}$} & \multirow{2}{*}{$\begin{array}{c}\text { Standardized } \\
\text { Coefficients } \\
\text { Beta }\end{array}$} & \multirow[b]{2}{*}{$\mathrm{t}$} & \multirow[b]{2}{*}{ Sig. } & \multicolumn{2}{|c|}{$\begin{array}{c}\text { Collinearity } \\
\text { Statistics }\end{array}$} \\
\hline & & $\mathrm{B}$ & Std. Error & & & & Tolerance & VIF \\
\hline 1 & (Constant) & 4,227 & 3,906 & & 1,082 & ,286 & & \\
\hline & Pelatihan &, 727 &, 193 & ,376 & 3,775 & ,001 & ,632 & 1,583 \\
\hline & Pengembangan & ,777 & ,277 & ,332 & 2,800 & ,008 & ,446 & 2,243 \\
\hline & $\begin{array}{l}\text { Teknologi } \\
\text { Informasi }\end{array}$ &, 537 & , 189 & ,308 & 2,845 &, 007 &, 535 & 1,870 \\
\hline & ependent Variab & ja Karyau & & & & & & \\
\hline
\end{tabular}

\section{Sumber : data Primer Diolah, 2021}

Berdasarkan tabel 3, persamaan regresinya adalah sebagai berikut :

$\mathrm{Y}=4,227+0,727 \mathrm{X} 1+0,777 \mathrm{X} 2+0,573 \mathrm{X} 3$

1. Nilai konstanta (a) $=4,227$ artinya jika Pelatihan, pengembangan, dan teknologi informasi menunjukan nilai (0) maka kinerja karyawan (Y) akan naik sebesar 4,227. 
2. Koefisien variabel $\mathrm{b} 1=0,727$ artinya jika pelatihan naik sebesar $1 \%$ dimana pengembangan, dan teknologi informasi maka kinerja karyawan akan naik sebesar 0,727.

3. Koefisien variabel $\mathrm{b} 2=0,777$ artinya jika pengembangan naik sebesar $1 \%$ dimana pelatihan, dan teknologi informasi maka kinerja karyawan akan naik sebesar 0,777 .

4. Koefisien variabel $\mathrm{b} 3=0,537$ artinya jika teknologi informasi naik sebesar $1 \%$ dimana pelatihan, dan pengembangan maka kinerja karyawan akan naik sebesar 0,537 .

\section{d. Koofisien korelasi}

Tabel 4. Koofisien korelasi

\begin{tabular}{|c|c|c|c|c|c|}
\hline \multicolumn{6}{|c|}{ Correlations } \\
\hline & & Pelatihan & Pengembangan & $\begin{array}{l}\text { Teknologi } \\
\text { Informasi }\end{array}$ & $\begin{array}{c}\text { Kinerja } \\
\text { Karyawan }\end{array}$ \\
\hline \multirow[t]{3}{*}{ Pelatihan } & Pearson Correlation & 1 &, $598^{\star \star}$ &, $479^{* *}$ &, $721^{\star \star}$ \\
\hline & Sig. (2-tailed) & &, 000 &, 001 & ,000 \\
\hline & $\mathrm{N}$ & 45 & 45 & 45 & 45 \\
\hline \multirow[t]{3}{*}{ Pengembangan } & Pearson Correlation &, $598^{\star \star}$ & 1 &, $676^{* *}$ &, $764^{* *}$ \\
\hline & Sig. (2-tailed) &, 000 & &, 000 &, 000 \\
\hline & $\mathrm{N}$ & 45 & 45 & 45 & 45 \\
\hline \multirow[t]{3}{*}{ Teknologi Informasi } & Pearson Correlation &, $479^{* \star}$ & $676^{* *}$ & 1 &, $712^{* *}$ \\
\hline & Sig. (2-tailed) & ,001 &, 000 & &, 000 \\
\hline & $\mathrm{N}$ & 45 & 45 & 45 & 45 \\
\hline \multirow[t]{3}{*}{ Kinerja Karyawan } & Pearson Correlation &, $721^{* *}$ &, $764^{* *}$ &, $712^{* *}$ & 1 \\
\hline & Sig. (2-tailed) &, 000 &, 000 &, 000 & \\
\hline & $\mathrm{N}$ & 45 & 45 & 45 & 45 \\
\hline
\end{tabular}

Sumber: data Primer Diolah, 2021

Berdasarkan tabel 5. Uji koefisien korelasi menunjukan nilai signifikansi $<0,5$ maka hasilnya berkorelasi 0,000 $<0,5$ maka terdapat hubungan antara pelatihan pengembangan teknologi informasi terhadap kinerja karyawan. Dan untuk derajat hubungan, nilai pearson Correlation sebesar:

1. 0,721 artinya tingkat hubungan antara Pelatihan terhadap kinerja karyawan adalah korelasi kuat.

2. 0,764 artinya tingkat hubungan antara pengembangan terhadap kinerja karyawan adalah korelasi kuat.

3. 0,712 artinya tingkat hubungan antara teknologi informasi terhadap kinerja karyawan adalah korelasi kuat.

Tabel 5. Pedoman Tingkat Pengaruh

\begin{tabular}{ll}
\hline Interval Koofisien & Tingkat Pengaruh \\
\hline $0,00-0,199$ & Sangat Rendah \\
$0,20-0,399$ & Rendah \\
$0,40-0,599$ & Sedang \\
$0,60-0,799$ & Kuat \\
$0,80-1,000$ & Sangat Kuat \\
\hline \multicolumn{2}{c}{ Sumber: Sugiyono 2016 }
\end{tabular}

\section{e. Koefisien Determinasi}

Tabel 5. Hasil koefisien determinasi

\begin{tabular}{|c|c|c|c|c|c|}
\hline \multicolumn{6}{|c|}{ Model Summaryb } \\
\hline Model & $\mathrm{R}$ & R Square & $\begin{array}{l}\text { Adjusted R } \\
\text { Square }\end{array}$ & $\begin{array}{l}\text { Std. Error of the } \\
\text { Estimate }\end{array}$ & Durbin-Watson \\
\hline 1 &, $862^{\mathrm{a}}$ &, 744 &, 725 & 3,113 & 1,990 \\
\hline
\end{tabular}

Berdasarkan tabel 6. Hasil uji koefisien determinasi olah data SPSS nilai R Square yaitu sebesar 0,744. Artinya kontribusi pengaruh antara pelatihan pengembangan teknologi informasi terhadap skil/kinerja karyawan yaitu sebesar $74,4 \%$ sedangkan sisanya $26,6 \%$ dipengaruhi oleh faktor - faktor lain yang tidak diteliti dalam penelitian ini. 


\section{f. Uji t}

Tabel 5. Hasil uji $\mathrm{t}$

\begin{tabular}{|c|c|c|c|c|c|}
\hline \multirow[b]{3}{*}{ Model } & \multicolumn{3}{|c|}{ Coefficients $^{\mathrm{a}}$} & \multirow[b]{3}{*}{$\mathrm{t}$} & \multirow[b]{3}{*}{ Sig. } \\
\hline & \multicolumn{2}{|c|}{$\begin{array}{l}\text { Unstandardized } \\
\text { Coefficients }\end{array}$} & \multirow{2}{*}{$\begin{array}{l}\text { Standardized } \\
\text { Coefficients } \\
\text { Beta }\end{array}$} & & \\
\hline & $\mathrm{B}$ & Std. Error & & & \\
\hline $1 \quad$ (Constant) & 4,227 & 3,906 & & 1,082 & ,286 \\
\hline Pelatihan &, 727 &, 193 & ,376 & 3,775 & ,001 \\
\hline Pengembangan & 777 & 277 & 332 & 2,800 & ,008 \\
\hline $\begin{array}{l}\text { Teknologi } \\
\text { Informasi }\end{array}$ & ,537 &, 189 & ,308 & 2,845 & ,007 \\
\hline a. Dependent Varial & nerja Kar & yawan & & & \\
\hline
\end{tabular}

Sumber: data Primer Diolah, 2020 berikut :

Berdasarkan hasil olah data statistic dengan spss yang ditunjukan pada tabel 5 maka dapat disimpulkan sebagai

1. Hasil perhitungan uji t menggunakan SPSS Versi 23 tahun 2021, maka didapatkan hasil t hitung sebesar 3,774 dan $t$ tabel sebesar 2,016. Sehingga nilai t tabel lebih besar dari nilai t hitung $(3,775>2,016)$. Berdasarkan hal tersebut diperoleh hasil $\mathrm{H}_{0}$ ditolak Ha diterima dimana terdapat pengaruh antara pelatihan (X1) terhadap Kinerja Karyawan (Y) pada KPN “Jaya” Guru SDN RABA.

2. Hasil perhitungan uji t menggunakan SPSS Versi 23 tahun 2021, maka didapatkan hasil t hitung sebesar 2,800 dan $t$ tabel sebesar 2,016. Sehingga nilai t tabel lebih besar dari nilai t hitung $(2,800>2,016)$. Berdasarkan hal tersebut diperoleh hasil $\mathrm{H}_{0}$ ditolak Ha diterima dimana terdapat pengaruh antara Pengembangan (X2) terhadap Kinerja Karyawan (Y) pada KPN "Jaya” Guru SDN RABA.

3. Hasil perhitungan uji t menggunakan SPSS Versi 23 tahun 2021, maka didapatkan hasil t hitung sebesar 2,845 dan $t$ tabel sebesar 2,016. Sehingga nilai t tabel lebih besar dari nilai t hitung $(2,845>2,016)$. Berdasarkan hal tersebut diperoleh hasil $\mathrm{H}_{0}$ ditolak Ha diterima dimana terdapat pengaruh antara Teknologi Infomasi (X3) terhadap Kinerja Karyawan (Y) pada KPN “Jaya” Guru SDN RABA.

\section{KESIMPULAN}

Dari hasil analisa data yang telah dilakukan dapat di tarik kesimpulan dalam penelitian yaitu hasil perhitungan uji $\mathrm{t}$ menggunakan SPSS Versi 23 tahun 2021, maka didapatkan hasil t hitung sebesar 3,774 dan t tabel sebesar 2,016. Sehingga nilai t tabel lebih besar dari nilai t hitung $(3,775>2,016)$. Berdasarkan hal tersebut diperoleh hasil $\mathrm{H}_{0}$ ditolak Ha diterima dimana terdapat pengaruh antara pelatihan (X1) terhadap Kinerja Karyawan (Y) pada KPN "Jaya" Guru SDN RABA. Hasil perhitungan uji t menggunakan SPSS Versi 23 tahun 2021, maka didapatkan hasil t hitung sebesar 2,800 dan t tabel sebesar 2,016. Sehingga nilai t tabel lebih besar dari nilai t hitung $(2,800>2,016)$. Berdasarkan hal tersebut diperoleh hasil $\mathrm{H}_{0}$ ditolak Ha diterima dimana terdapat pengaruh antara Pengembangan (X2) terhadap Kinerja Karyawan (Y) pada KPN “Jaya” Guru SDN RABA. Hasil perhitungan uji t menggunakan SPSS Versi 23 tahun 2021, maka didapatkan hasil $\mathrm{t}$ hitung sebesar 2,845 dan $\mathrm{t}$ tabel sebesar 2,016. Sehingga nilai t tabel lebih besar dari nilai $\mathrm{t}$ hitung $(2,845>2,016)$. Berdasarkan hal tersebut diperoleh hasil $\mathrm{H}_{0}$ ditolak $\mathrm{Ha}$ diterima dimana terdapat pengaruh antara Teknologi Infomasi (X3) terhadap Kinerja Karyawan (Y) pada KPN “Jaya” Guru SDN RABA.

\section{REFERENCES}

Alvina Ghina Riyanita, Harjanti Widiastuti Jurnal Akuntansi Bisnis, Vol. 18, No. 1, Maret 2020. ISSN 1412-775X (media cetak) 2541-5204 (media online)

Amir, Syafar, dan Kaseng. 2016. Pengaruh Karakteristik Individu, Motivasi Dan Beban kerja Terhadap Kinerja Pegawai Di Rumah Sakit Daerah Madani Provinsi Sulawesi Tengah. EJurnal Katalogis. Volume 4 No. 7 Juli 2016

Anwar Prabu Mangkunegara, 2008. Manajemen Sumber Daya manusia, Perusahaan. Bandung : Rosda

A.Sudrajat. Universitar Bina Sarana Informatika (Naskah diterima: 1 Januari 2020, disetujui: 1 Februari 2020) Jurnal AKRAB JUARA Volume 5 Nomor 1 Edisi Februari 2020 (150-159)

Budhi, I Gede KT. Tjahyadi. (2018). Pengaruh Teknologi Informasi Terhadap Budaya Organisasi dan Kinerja Karyawan Di STMIK Stikom Bali. Jurnal Media Aplikasi.Jurnal Media Aplikom, 10(2):113-134

Edy, Sutrisno. (2016). Manajemen Sumber Daya Manusia. Kencan Prenada Media Group. Jakarta

Edy Sutrisno. 2011. Manajemen Sumber Daya Manusia. Jakarta: Prenada Media Group. 
Fatimah. 2013. Pengaruh Pelatihan, Dukungan Manajemen Puncak danKejelasan Tujuan Terhadap Efektivitas Sistem Informasi Akuntansi Keuangan Daerah (Studi Empiris pada DPKAD Kota di Sumatera Barat). Program Studi Akuntansi Fakultas Ekonomi Universitas Negeri Padang

Genot Agung Busono Dosen Tetap Fakultas Ekonomi dan Bisnis UMPalembang MUQTASHID, Vol. I, No. 01, Edisi Maret 2016

Hasibuan, Malayu S.P. 2013. Manajemen Sumber Daya Manusia. Jakarta: PT. Bumi Aksara.

Mustafa, Santiadji, dkk. 2010. Analisis Faktor-Faktor Yang Berpengaruh Terhadap Keterandalan Dan Ketepatwaktun Pelaporan Keungan Pada SKPD Pemerintah Daerah Kota Kendari. Jurnal Akuntansi.

Oemar Hamalik. 2007. Pengembangan SDM Manajemen Pelatihan Ketenagakerjaan Pendekatan Terpadu. Jakarta : Bumi Aksara

Robbins, Stephen P., Timothy A. Judge. (2016). Perilaku Organisasi Edisi 16. Jakarta : Salemba Empat. 